\title{
The influence of types of character on processing background information in narrative discourse
}

\author{
ANTHONY J. SANFORD, MICHAEL CLEGG, and ASIFA MAJID \\ University of Glasgow, Glasgow, Scotland
}

\begin{abstract}
The background sentence The air was cold and clammy depicts setting information which may or may not be of significance to a given character in a narrative. We tested the hypothesis that such information is processed with respect to the main character in a narrative rather than with respect to a secondary character. In Experiment 1, subjects making attributions of awareness of such background states were more likely to attribute such awareness to main than to secondary characters. In Experiment 2, using self-paced reading, we showed that such information is more important for main than for secondary characters during reading. Thus, unattached background information is processed with respect to main characters. This bias provides a source of control over the processing necessary to establish a coherent representation during the reading of narratives. Experiment 3 eliminated the possibility that the effects were due to generally shallower processing of sentences centered on secondary characters.
\end{abstract}

It is commonplace for narratives to have a story line that is based on the goals and actions of a principal protagonist, or main character, with secondary characters being introduced only as they become relevant to the main protagonist. Another common feature is the presence of background information sentences, such as $I t$ was a beautiful day, or The air was humid. In this paper, we propose that such background information sentences tend to be processed with respect to the characters, and that those characters are more likely to be main, rather than secondary, characters.

In novels and long pieces of narrative, the importance of main characters appears self-evident. They carry the story line in that their goals and realizations form the causal backbone, whereas secondary characters tend to play more fragmented roles, sometimes even becoming the equivalents of props rather than characters proper (see Zubin \& Hewitt, 1995, pp. 138-140). This view is expressed most obviously in the formulation of the story grammar (see, e.g., Mandler, 1984; Rumelhart, 1975; Thorndyke, 1977), in which the thread of a story is taken to be based on the protagonist's goal.

Literary studies of narrative have explored the idea that narratives are typically understood from the point of view of a specific individual, the focalizer (Genette, 1980; also Toolan, 1988, pp. 67-83). Among other things, the focalizer can be the writer as narrator; or in texts that are explicitly narrated, a person set up in the text to be a narrator may be the focalizer. Whoever the focalizer may be,

This research was supported by Grant R000221462 to the first and second authors from the U.K. ESRC. Thanks are due Morton Gernsbacher, Art Glenberg, and an anonymous reviewer for very helpful comments on an earlier version. Thanks are also due Cathy Emmott for discussions about literary studies of focalization. Correspondence should be addressed to A. J. Sanford, Department of Psychology, University of Glasgow, Glasgow G12 9YR, Scotland (e-mail: tony@psy.gla.ac.uk). it is generally claimed within narratology that somebody must play that role because of the numerous possible interpretations that might be imposed on scenes and events (see Genette, 1980). With longer natural narratives, explicit cues may indicate who the focalizer is (see, e.g., Wilkins, 1995; Zubin \& Hewitt, 1995). With very simple texts like those used in the present study, no explicit cues are provided. However, even with short texts, main characters are typically apparent, and we suggest that main characters will typically be focalizers, rather than secondary characters.

Previous psychological work by Morrow (1985) has shown that ambiguous pronouns are typically taken as referring to main characters rather than to secondary characters in narratives, suggesting that the former may be focalizers. In fact, most existing empirical work on focalizers has concentrated on anaphoric and other reference devices (Hewitt, 1995) as a means of both identifying the focalizer and understanding the process of taking a perspective. (In anaphora, one expression is used to refer back to something previously mentioned in the text.) In the present research, we propose that there is another way of identifying the focalizer: to test whether background information is taken as being experienced (noticed by, or otherwise affecting) a character in a short text, even when there is no direct connection between that character and the background information.

On the basis of the literature on narratives, we would propose that a sentence like The air was hot and sticky would be interpreted as experienced by a character in a text, and that the attribution of such experience would be more likely to a main character than to a secondary one, on the grounds that main characters have been identified within narratology as being the typical focalizer in simple stories with no direct perspective cues. The question addressed in Experiment 1 is whether a subject would be more likely to answer "yes" to the question of whether a 
main character "felt the air was hot and sticky" than to the same question asked of a secondary character.

The background sentences that we consider here have three major properties. First, they are backgrounded in a linguistic sense, in that they are not temporally delineated and are, typically, descriptions of scenes or mental and emotional states, elaborations, or explanations (Hopper \& Thompson, 1980; Smith, 1995). Second, they are unattached, in that their content is not directly linked to a character, and any such link has to be inferred. So, given the sentences Harry listened to the talk and The air was hot and sticky, an inference would be necessary in order to form a link with Harry, through representation of the type Harry experiences the hot and sticky atmosphere. Logically, there is no need to draw this inference, of course. Finally, such background states are potentially applicable to any character introduced, because our materials are such that they are not directly related to any stated goals and actions of the characters.

An additional feature of our materials is that some of them require a character's perspective in order to be properly processed. Thus The air was hot and sticky has a "psychological" predicate, in that to evaluate its truth it is necessary to check whether some experiencer finds the air to be hot and sticky. We compare the processing of these psychological statements with other kinds of background information sentences that do not have psychological predicates. For instance, the objective statement There was a band playing in the bandstand does not have a psychological predicate, because it does not require an experiencer. However, it is still possible that the information can be coded with respect to a character (experiencer). In Experiment 1, we tested whether there is any difference between the ways in which the two predicate types, objective and psychological, are processed.

In the present studies, the status of main versus secondary character is operationalized through the type of description used to introduce the characters. Main character status is associated with the use of a proper name (such as Mary), whereas secondary character status is associated with a role description (such as The waitress). Sanford, Moar, and Garrod (1988) used short two-character texts, introducing one character by means of a proper name and the other by means of a noun phrase. For proper-named individuals, the frequency of mention in a continuation task and the speed of processing anaphoric reference sentences in a self-paced reading time task were both overwhelmingly enhanced, while order of mention and other variables were much less important (see also Sanford \& Lockhart, 1991). With longer texts, other variables such as frequency of mention will almost certainly be important, but with very short texts, the use of a proper name is such a powerful determinant of main characterhood, and such a simple thing to vary, that it is used as the principal means of manipulating character status in the present experiments.

In Experiment 1, we tested directly the idea that the states of affairs depicted by background sentences would be interpreted as perceived by a character introduced in the text. Subjects responded "yes," "no," or "don't know" to questions of attribution. The inclusion of a "don't know" response option meant that subjects were not forced to make an attribution of awareness to a character; for instance, it is possible that the narrator (writer) would be taken as the focalizer (Genette, 1980), in which case no "yes" responses should be made. In addition, we tested the proposal that the main character would be the focalizer. Finally, we checked for any differential effects between psychological and objective predicates.

\section{EXPERIMENT 1}

\section{Method}

Design and Materials. Two sets of 32 vignettes were designed, one containing psychological and one objective background statements. An example is shown in Table 1. The first sentence introduced one of the characters, and the next the other. A character was described by a proper name or by a role description: The character introduced through the proper name was the main character. The third sentence introduced the critical background psychological or objective statement. The final sentence was a filler comprising further backgrounded information. The question asked whether the critical sentence information was experienced by the main or the secondary character.

The design was 2 (psychological vs. objective) $\times 2$ (character named) $\times 2$ (order of characters) $\times 2$ (character probed).

Subjects. There were 40 unpaid volunteer subjects. All were undergraduates of the University of Glasgow. No subject had taken part in any similar study, and no subject was aware of the purpose of the study.

Procedure. The experiment was carried out on an Apple Macintosh computer running the PsyScope package (Cohen, MacWhinney, Flatt, \& Provost, 1993). Presentation of materials was visual, sentence by sentence, and at a rate controlled by the subject pressing the space bar of a keyboard. Each time a new sentence was called, the previous sentence disappeared. After the last line of a passage was read, the question was displayed. The subjects responded by pressing one of three keys for "yes," "no," and "don't know." PsyScope presentation was used to ensure that subjects did not have the whole passage in front of them when they came to answer the question, and to encourage rapid responding.

Table 1

Example Vignettes for Experiment 1

Hill Walking

Psychological Predicate

\{Malcolm/A man\} took out his map.

\{Mary/A woman\} examined their route.

The air was beautifully fresh and clear.

The sun had barely risen yet.

**QUESTION**

Did (Malcolm/the man/Mary/the woman \} find the air fresh and clear?

Objective Predicate

The Museum

\{Mary/A woman $\}$ was studying the seventeenth century Dutch portraits.

\{A tour guide/Tom\} strolled around the gallery.

In one corner a student was copying an Old Master.

The museum was unusually busy for a weekday.

** QUESTION**

Did $\{$ Mary/The woman/Tom/The tour guide $\}$ notice the student copying the Old Master? 
A given subject saw a particular vignette in only one of its eight possible variants; by rotation, each material was seen in a given variation by 5 subjects. The vignettes were presented in a new random order for each subject. The subjects saw five practice items before the main experiment.

\section{Results and Discussion}

The percentages of responses in each class are shown in Table 2. Despite having the option of "don't know," which is the strictly logical answer, subjects made attributions of awareness on $46 \%$ of the trials, indicating that a character-based perspective was being adopted.

Since response frequencies in different classes are related with any two of defining the third, further analyses of "yes" responses only are given. ANOVAs were carried out by subjects and materials on the proportion data after arcsin transformation. There was a differential attribution effect: more "yes" responses were to questions about main characters than about secondary characters $\left[F_{1}(1,39)=\right.$ $27.4, M S_{\mathrm{e}}=.491, p<.001$, and $F_{2}(1,62)=73.8, M S_{\mathrm{e}}=$ $.113, p<.0001]$, as hypothesized. There was also a main effect of type of background sentence. The psychological sentences led to more "yes" responses than did the objective sentences $\left[F_{1}(1,39)=14.3, M S_{\mathrm{e}}=.573, p<.001\right.$, and $\left.F_{2}(1,62)=25.1, M S_{\mathrm{e}}=.220, p<.0001\right]$. There were no other significant main effects or interactions.

The results present a simple picture. First, there was evidence of making attributions of awareness to text characters, suggesting that text characters are sometimes focalizers. Second, there was a reliable bias toward the main character over the secondary one in terms of "yes" responses, revealed through the interaction. Finally, the attribution bias held for objective as well as psychological predicates, and so was not just a result of psychological predicates forcing the adoption of an "experiencer" as part of their interpretation: Adoption of experiencers also occurred when it was not necessary. However, attribution ("yes" responses) did occur at a lower rate for objective predicates, so psychological predicates do appear to have been more likely to trigger them.

Although these results are consistent with an attribution bias toward the main character, we explicitly required subjects to check the feasibility of attribution. In Experiment 2 , we used self-paced reading to determine whether background information would be more important in the processing of main-character- rather than secondarycharacter-centered sentences. The critical sentence was

Table 2

Percentages of "Yes," "No," and "Don't Know" Responses in Experiment 2 (Collapsed Over Orders of Character)

\begin{tabular}{lccccc}
\hline & \multicolumn{3}{c}{ Condition } \\
\cline { 2 - 3 } \cline { 5 - 6 } \multicolumn{1}{c}{ Response } & Main & Secondary & & Main & Secondary \\
\cline { 2 - 3 } "Yes" & 54 & 46 & & 49.5 & 36 \\
"No" & 10 & 17 & & 16 & 21 \\
"Don't know" & 26 & 37 & & 34.5 & 43 \\
\hline
\end{tabular}

one in which the action of one of the protagonists was either consistent or not consistent with the information delivered in an earlier background information sentence. If the background information was attached to the protagonist in question, an inconsistent action should produce a disruption in processing, resulting in a slower reading time. For instance, consider the following pair of sentences:

\section{(1) The show was [very tedious/very funny]} [brackets contain options]

( $\left.1^{\prime}\right)$ Patricia yawned several times.

To the extent that (1) contains information that is classed as relevant to the action depicted in $\left(1^{\prime}\right)$, the ease of integrating the two sentences should depend on the fit of $\left(1^{\prime}\right)$ to $(1)$. Thus very tedious should facilitate integration, whereas very funny should not, and this should be reflected in reading time. In the presence of such a consistency effect, we could establish whether disruption was more likely to occur with main characters, corresponding to the attribution pattern found in Experiment 1. A larger consistency effect for targets containing main characters would suggest that the utilization of the background information was more likely to occur with main characters.

\section{EXPERIMENT 2}

\section{Method}

Materials. The initial materials consisted of 24 vignettes, reduced to 20 after a pretest. An example vignette is shown in Table 3 . The first line introduced one character, and the second line another. One of the characters was introduced through a proper name (the main character), and the other through a simple noun phrase (the secondary character). The third sentence consisted of a psychological background information sentence. Because the incidence of at tribution was higher in the psychological sentences than in the objective sentences, the background information sentences were restricted to those with psychological predicates. The fourth, the target sentence, was an action on the part of one of the characters which was either highly consistent with the background information sentence or not. The final sentence was a filler.

Because each character appeared in both the named and the noun phrase condition, any differential effects of the background sentence could not be ascribed to different states of adaptation or interest on the part of the main or the secondary character.

Pretest. The design hinges on the fit of the action depicted in the target sentence to the atmosphere statement. A pretest was carried out to establish that the expected match and mismatch pattern was perceived by a group of subjects. Four sets of booklets contained vignettes truncated at the target sentence verb (in our example, at yawned). Each booklet contained 24 vignettes, with 6 in each of the four experimental conditions. The four sets of booklets made it possible to present every vignette in each condition, while ensuring that a given subject saw each vignette only once. The 40 subjects were asked to rate how well the final pronoun and verb (e.g., She yawned) in each vignette fit what had preceded it. They answered on a scale from 1 (poor fit) to 7 (good fit). The 20 best-performing vignettes gave mean ratings of 5.8 for the high-consistency configurations (minimum 4.6), and 2.5 for the low-consistency configu- 
Table 3

Example Vignette for Experiment 2

The bank

The teller/Alastair called the next customer to his window.

Margaret/A woman stood at the head of the queue.

\{The atmosphere was airy and refreshing. \}

\{The atmosphere was airless and oppressive.

$\mathrm{He} /$ She fainted suddenly against a marble pillar. Target

Another customer came to her aid

Does the bank have wooden pillars?

Note-The brackets and slashes denote alternatives.

rations (maximum 3.2). There was thus no overlap, and these 20 items were used in the main study.

Design. There were four main conditions, formed by crossing the two independent variables of target sentence referent (main or secondary character) and consistency (high or low). In addition, for a given vignette, which character was named, and which was introduced through a role description, allowed for a further two-level factor in the design. Eight files of materials were created. A given file contained all 20 vignettes, with 5 allocated to each condition. By rotation over the eight files, each vignette appeared in all conditions over the files, but only once within a file. In addition, 20 filler vignettes were included, each consisting of a title and five sentences, with variable numbers of characters. These were included to prevent subjects from predicting the structure of materials and developing special strategies. A given file was randomly assigned to 3 of the 24 subjects. One half of the vignettes in each file were followed by a comprehension question querying an aspect of the vignette, half requiring a "yes" and half a "no" answer.

Subjects. There were 24 subjects, unpaid volunteer undergraduates from the University of Glasgow. None had participated in any related study, and all were naive with respect to the aims of the study.

Procedure. The experiment was carried out on an Apple Macintosh running PsyScope software. Text was displayed in 12-point Chicago font with a fixed left-hand margin. Responses were made with a standard Carnegie Mellon button box, which had three buttons: left, center, and right.

The presentation of passages was self-paced, one sentence at a time. Depressing the center button of the button box caused the next sentence to appear, terminated the recording of the previous reading time, and initiated the measurement of the reading time to the current sentence. Each passage began with an asterisk fixation spot. If a question was asked, responses were made by the subject pressing either a "yes" or a "no" key. The subjects were instructed to read as quickly as was consistent with comprehension. Four practice trials preceded the main body of the experiment.

\section{Results and Discussion}

The error rate for questions was $5 \%$, so it can be assumed that subjects were reading adequately. There was no reliable difference in the number of errors made as a function of condition.

Mean target reading times are shown in Figure 1. ANOVAs showed that there was no main effect of character $\left(F_{1}\right.$ and $\left.F_{2}<1\right)$. However, there was a main effect of consistency [ $276 \mathrm{msec}, F_{1}(1,23)=20.79, M S_{\mathrm{e}}=$ $88,236.2, p<.001 ; F_{2}(1,19)=15.44, M S_{\mathrm{e}}=90,559.7$, $p<.001]$, as anticipated. The interaction between character and consistency was reliable $\left[F_{1}(1,23)=7.054\right.$, $M S_{\mathrm{e}}=27,194.8, p<.02 ; F_{2}(1,19)=7.02, M S_{\mathrm{e}}=$ $34,491.6, p<.02]$. No other effects approached reliability.
The observed interaction shows that the attribution effect holds during comprehension and in the absence of a specific attribution probe question. It was explored further by using means comparisons. The contrasts between high- and low-consistency held for both main and secondary character referents [main $F_{1}(1,23)=59.1, M S_{\mathrm{e}}=$ $1,606,392, p<.001 ; F_{2}(1,19)=40.7, M S_{\mathrm{e}}=1,402,047$, $p<.001$; secondary, $F_{1}(1,23)=15.4, M S_{\mathrm{e}}=419,914$, $\left.p<.001 ; F_{2}(1,19)=6.9, M S_{\mathrm{e}}=238,115, p<.02\right]$. Comparisons were also made at the two levels of consistency. With high-consistency transitions, targets referring to main characters were read a reliable $115 \mathrm{msec}$ faster than targets referring to secondary characters $\left[F_{1}(1,23)=\right.$ $5.86, M S_{\mathrm{e}}=159,338, p<.025 ; F_{2}(1,19)=4.26, M S_{\mathrm{e}}=$ $146,757, p=.053]$. With low-consistency transitions, the main character reading times were some $63 \mathrm{msec}$ slower than the secondary character times, but the effect was not reliable $\left[F_{1}(1,23)=1.78, M S_{\mathrm{e}}=48,511\right.$, n.s.; $\left.F_{2}(1,19)=2.8, M S_{\mathrm{e}}=97,982, p<.1\right]$.

The results confirm the differential processing of background sentences with psychological predicates in the absence of a direct probe question. This fits the idea that the information is more central to the actions of the main, as opposed to the secondary, characters. We propose that the differential obtained may be ascribed to a greater tendency for background to be processed with respect to the main character. In order to create a consistency effect, it is necessary that the psychological predicate information is understood as being experienced by the character, and this is more likely for main characters, consistent with the off-line probe results of Experiments 1 and 2.

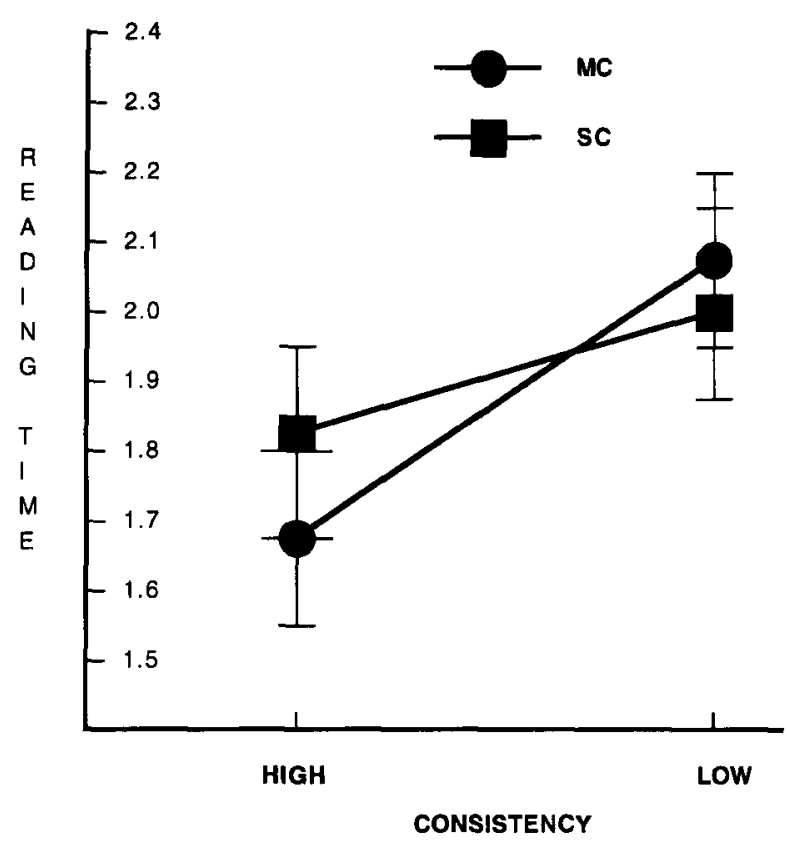

Figure 1. Mean reading times in seconds for target sentences in Experiment 2, with standard error bars. MC, main characters; SC, secondary characters. 
There is another possibility, however. In Experiment 2 , the design of the materials was such that a link between the background and the target sentence had to be inferred. This was essential in order to test our claim that this inferential link is the basis of the differential effect of consistency for the two character types. But it is possible that secondary-character-centered sentences are always processed in a more shallow way than main-charactercentered ones are, and that a failure to use possibly relevant background information is just one manifestation of more generalized shallow processing. Certainly there is evidence of shallower processing of semantic information and subsidiary clauses of complex sentences (Baker \& Wagner, 1987), and for elements of a sentence that are not in focus (Bredart \& Modolo, 1988), and the same might hold for sentences centered on the actions of secondary characters. In Experiment 3, we tested this possibility by using materials in which there was a direct link between the background information sentence and the target sentence, through an obvious cohesion marker. An example is given below:

(2) Some tourists were asking for directions in halting French.

$\left(2^{\prime}\right)$ Pierre laughed at their attempt to speak French.

Here there is a referential link between the two sentences, in that Pierre is laughing at their attempt. Thus the sentence forces the conclusion that Pierre noticed the tourists' efforts. No such links occurred in the materials for Experiment 2, in which the very point of the study was to investigate how attributions of noticing occurred in the absence of such direct links. In the materials for Experiment 3, there was no need to infer a connection between background and target. If a main/secondary character differential in consistency still occurred, the results of Experiment 3 could be ascribed to generalized shallow processing of secondary-character-centered sentences. On the other hand, lack of a differential would make such an explanation unlikely and would support our preferred interpretation.

\section{EXPERIMENT 3}

\footnotetext{
Method

Design and Procedure. The design and procedure were identical with those of Experiment 2. The materials were analogous to those in Experiment 2, except that the background sentences introduced an action, and, critically, the target sentences contained a direct reference to the agent of that sentence, or an overt argument repetition based on that sentence. An example vignette is provided in Table 4.

Pretest. The materials were pretested to establish the fit or otherwise of the action sentence and target sentence. The procedure was analogous to that in Experiment 2, except that the whole target sentence was presented for the test of fit. High-consistency configurations gave mean ratings of 6.3 (minimum 5.1); low-consistency configurations, a mean of 2.4 (maximum 4 ). Thus there was no overlap.

Subjects. There were 24 unpaid volunteer subjects, from the University of Glasgow. None had participated in any related study, and all were naive with respect to the aims of the study.
}

Table 4

Example Vignette for Experiment 3

\section{Swimming}

The Woman Pool Attendant/Nadia watched everyone from the observation seat.

Jeffrey/A man stood next to the deep end of the pool.

(A couple of boys swam a length in thirty seconds)

(A couple of boys took more than three minutes to swim a length)

She/He complimented them on their speed. Target

Some kids yelled with delight as they played in the water.

\section{Results}

Error rates for the questions were low at $6 \%$ overall, indicating that subjects were reading adequately for comprehension. Mean reading times for the target sentences are shown in Figure 2. The results are markedly different from those obtained in Experiment 2. There was a main effect of consistency $\left[F_{1}(1,23)=10.7, M S_{\mathrm{e}}=160,509\right.$, $\left.p<.004 ; F_{2}(1,19)=5.4, M S_{\mathrm{e}}=262,981, p<.04\right]$; highly consistent statements were read more quickly than lowconsistent ones. There was a numerical but statistically unreliable main effect of character type. Sentences in which the reference was to the main character were read faster than sentences in which there was a reference to the secondary character $\left[F_{1}(1,23)=3.8, M S_{\mathrm{e}}=107,334.7\right.$, $\left.p<.063 ; F_{2}(1,19)=2.69, M S_{\mathrm{e}}=126,585.2, p<.12\right]$. Most importantly, however, there was no interaction between these two variables $\left[F_{1}(1,23)<.003 ; F_{2}(1,19)<\right.$ $.002]$. Indeed, the consistency effect was $264 \mathrm{msec}$ for the main characters, and $270 \mathrm{msec}$ for the secondary characters, only $6 \mathrm{msec}$ off perfect additivity. A power analysis based on the subject analysis gave a power of .772 to detect an interaction effect as large as that obtained in Experiment 2 in the present design, when $\alpha=.05$.

These results do not support a generalized shallow processing argument. We conclude that the pattern of interaction obtained in Experiment 2 resulted from a reduced tendency to form an inferential link connecting the background information to the secondary characters in comparison with the main characters, and not from general shallow processing of secondary-character-centered sentences. ${ }^{2}$

\section{GENERAL DISCUSSION}

The question of how to explain and characterize the perspectives taken by readers of narratives is central to the understanding of the nature of narration itself. An important concept in the theory of perspective taking is the concept of the focalizer (Genette, 1980) - the individual from whose point of view the narrative is to be understood. In some cases, it is clear who the focalizer is, though it can become very complex. For instance, if there is an explicit narrator within a text who is describing his own experiences as a youngster, there can be many subtle shades or shifts in the focalizer. The determination of the focalizer has been described as the essential issue in the study of narrative discourse (Toolan, 1988), and focalization is viewed as a key feature of the narrative genre. 


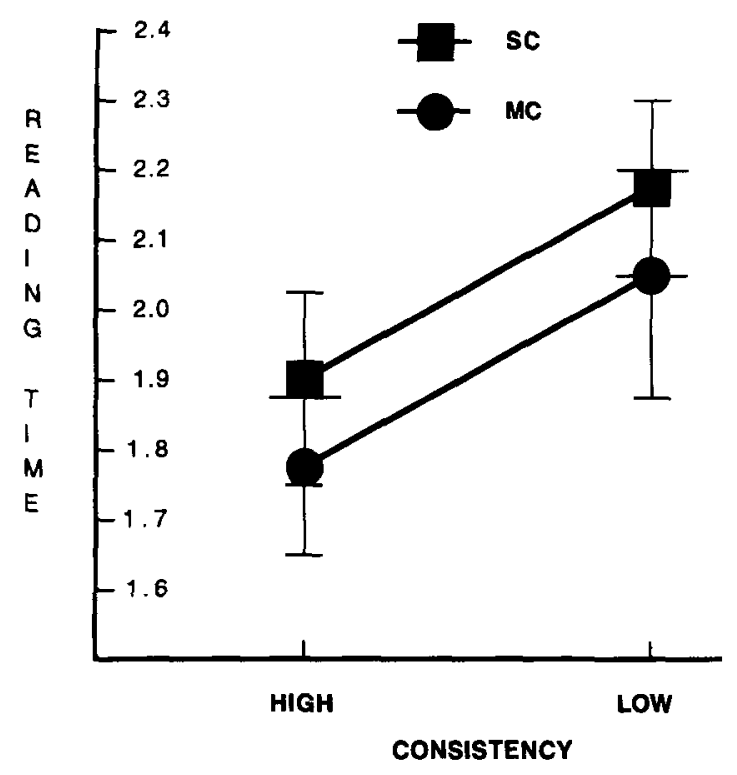

Figure 2. Mean reading times in seconds for target sentences in Experiment 3, with standard error bars.

Cues such as tense, deixis (perspective terms such as this vs. that), and degrees of direct and indirect reporting all can serve as potential controllers of focalization (Leech \& Short, 1981).

The observations of narrative theorists can be taken as specifying the properties of the input stimulus that constitute the category of narrative (Segal, 1995). Linguistic and corpus analysis provides one source of empirical data about the nature of narrative, and how focalization is triggered, but does not address the manner in which narrative is processed, which is more properly a psychological question. In addition, it is clear that focalization is a central issue for any psychological theory attempting to explain the flow of inferential activity that takes place during listening or reading; adopting a viewpoint provides a means of containing any potential inferential explosion.

Existing psychological studies have been successful in demonstrating perspectives triggered by within-text characteristics. Thus, Black, Turner, and Bower (1979) showed that sentences like John came into the room seem to force a within-room perspective, whereas John went into the room forces a perspective outside of the room. Subsequent sentences matching or mismatching these perspectives, although coherent, led to longer processing times and poorer retention. Black et al. ascribed the origin of the perspective (the focalizer) to the position of the narrator: with went, the narrator is outside, and with came, she is on the inside.

The present experiments are somewhat different, in that we have not been concerned with the point of view of the narrator, but rather with whether the point of view of a character is adopted in that the character is taken to be an experiencer of neutrally reported setting information. In fact, Genette (1980) was careful to separate conceptually the narrator from the focalizer in his analysis of these issues. The present Experiment 1 clearly shows that attributions of the experiencer are made to narrative characters, especially main characters. Experiment 2 shows that the fit of background information has a larger effect on main than on secondary characters, as is witnessed by the interaction of consistency and character type.

One question is how the present data integrate themselves with other known differences between main and secondary characters shown in psycholinguistic experiments. For instance, easier (faster) pronominal reference resolution is associated with main characters (Anderson, Garrod, \& Sanford, 1983; Sanford et al., 1988), and there is a preference to interpret ambiguous pronouns as referring to main characters, in the absence of strong cues to the contrary (Morrow, 1985). In the present Experiment 3 , there was a numerical if statistically weak trend of reading sentences centered on main characters faster than those centered on secondary characters. Such data could mean that the processing of sentences centered on secondary characters may be shallower in some way, as it is with subsidiary clauses, for instance (see, e.g., Baker $\&$ Wagner, 1987). This alone could explain the differential in the consistency effect obtained in Experiment 2. Experiment 3 showed that when a main or a secondary character is explicitly signaled as having awareness of some state of affairs, there is no difference in the impact that this information has. Thus the main/secondary character differential in Experiments 1 and 2 seems most likely due to a genuine differential attribution of awareness.

Our discussion brings to the surface a number of other questions concerning the status of the main and the secondary characters, and its relation to focalization. Zubin and Hewitt (1995), through the analysis of a literary example, show how a "character" (what they term a "who") can be highly personified, or can drop back to the status of a prop (what they term a "what" or even a "where"). One might expect that a high degree of personification would be necessary for an entity to be a focalizer. In the present studies, both main and secondary characters were associated with actions; secondary characters were never simply props, and this might explain why the main/secondary character differential was not greater.

The present studies go beyond patterns and ease of reference as a way of understanding a character's perspective in narrative by introducing the idea of the experiencer as an important aspect of focalization. It is recognized that focalization may include a whole range of attributional possibilities capturing characters' perceptions and reactions to events, and the fractionation of these may yield a better understanding of the processing that has been labeled focalization. For instance, if a deaf main character is portrayed as being in a narrative environment where someone has a shrill voice, what attributions might be made? We suspect that the connection to the 
main character would be something like main character was lucky not to be able to hear it. If this is true (and it is an empirical question), then, rather than readers modeling the actual perceptions of characters, in fact they may be simply checking the significance of background events for those characters. Where appropriate and possible, the significance may entail an assumption of perception on the part of the character, but this is not a necessary condition for the basic mechanism. On this view, in the present context, the process underlying focalization is the assessment of how background information can be related to characters, especially the main ones.

\section{REFERENCES}

Anderson, A., Garrod, S., \& SANFord, A. J. (1983). The accessibility of pronominal antecedents as a function of episode shift in narrative discourse. Quarterly Journal of Experimental Psychology, 35A, 427-440.

BAKER, L., \& WAGNER, J. L. (1987). Evaluating information for truthfulness: The effects of logical subordination. Memory \& Cognition, $15,247-255$.

Black, J. B., Turner, T. J., \& Bower, G. H. (1979). Point of view in narrative comprehension, memory and production. Journal of Verbal Learning \& Verbal Behavior, 18, 187-198.

BredArT, S., \& MoDolo, K. (1988). Moses strikes again: Focalization effects on a semantic illusion. Acta Psychologica, 67, 135-144.

Cohen, J., MacWhinney, B., Flatt, M., \& Provost, J. (1993) PsyScope: An interactive graphic system for designing and controlling experiments in the psychology laboratory using Macintosh computers. Behavior Research Methods, Instruments, \& Computers, 25, 257-271.

GenetTe, G. (1980). Narrative discourse: An essay on method (J. E. Lewin, Trans.). Ithaca, NY: Cornell University Press.

HewitT, L. E. (1995). Anaphor in subjective contexts in narrative fiction. In J. F. Duchan, G. A. Bruder, \& L. E. Hewitt (Eds.), Deixis in narrative: A cognitive science perspective (pp. 325-339). Hillsdale, NJ: Erlbaum.

HoPPER, P. J., \& THOMPSON, S. A. (1980). Transitivity and grammar in discourse. Language, 56, 251-299.

LEECH, G. N., \& SHORT, M. H. (1981). Style in fiction. Harlow, U.K.: Longman

MANDLER, J. M. (1984). Stories, scripts and scenes: Aspects of schema theory. Hillsdale, NJ: Erlbaum.
Morrow, D. G. (1985). Prominent characters and events organize narrative understanding. Journal of Memory \& Language, 24, 304-319.

RumelharT, D. E. (1975). Notes on a schema for stories. In D. G. Bobrow \& A. Collins (Eds.), Representation and understanding: Studies in cognitive science (pp. 211-236). New York: Academic Press.

SANFORD, A. J., \& LOCKHART, F. (1991). Description types and method of conjoining as factors influencing plural anaphora: A continuation study of focus. Journal of Semantics, 7, 365-378.

Sanford, A. J., Moar, K., \& Garrod, S. C. (1988). Proper names as controllers of discourse focus. Language \& Speech, 31, 43-56.

Segal, E. M. (1995). Narrative comprehension and the role of deictic shift theory. In J. F. Duchan, G. A. Bruder, \& L. E. Hewitt (Eds.), Deixis in narrative: A cognitive science perspective (pp. 3-17). Hillsdale, NJ: Erlbaum.

SMITH, C. S. (1995, June 23). Activity sentences in narrative: States or events? Paper presented to the Department of Cognitive Science, University of Edinburgh.

THORNDYKE, P. W. (1977). Cognitive structures in the comprehension and memory of narrative discourse. Cognitive Psychology, 9, 77-110.

TOOLAN, M. J. (1988). Narrative: A critical linguistic introduction. London: Routledge.

WILKINS, D. P. (1995). Expanding the traditional category of deictic elements: Interjections as deictics. In J. F. Duchan, G. A. Bruder, \& L. E. Hewitt (Eds.), Deixis in narrative: A cognitive science perspective (pp. 359-386). Hillsdale, NJ: Erlbaum.

Zubin, D. A., \& HEWITT, L. E. (1995). The deictic center: A theory of deixis in narrative. In J. F. Duchan, G. A. Bruder, \& L. E. Hewitt (Eds.), Deixis in narrative: A cognitive science perspective (pp. 129-155). Hillsdale, NJ: Erlbaum.

\section{NOTES}

1. The materials for all experiments may be obtained from the author on request.

2. A reviewer suggested that in the low-consistency condition, the materials were not really inconsistent, since they could be interpreted as ironic. The ratings given in the pretest showed that subjects did class the materials as inconsistent, and as inconsistent as those in the parallel condition of Experiment 2. Also, no pretest subject commented on irony as a possibility. The failure of interaction would not appear to be due to this explanation.

(Manuscript received January 28, 1997 revision accepted for publication August 22, 1997.) 